\title{
Indicator modelling and interactive visualisation for urban sustainability assessment.
}

\author{
FALCONER, R.E., ISAACS, J.P., GILMOUR, D. and BLACKWOOD, D.J.
}

2018

This chapter/paper appears in E-planning and collaboration: concepts, methodologies, tools and applications edited/authored by Information Resources Management Association Copyright 2018, IGI Global, www.igiglobal.com. Posted by permission of the publisher. 


\section{E-Planning and Collaboration:}

Concepts, Methodologies, Tools, and Applications

Information Resources Management Association USA

\section{Volume I}


Published in the United States of America by

IGI Global

Engineering Science Reference (an imprint of IGI Global)

701 E. Chocolate Avenue

Hershey PA, USA 17033

Tel: 717-533-8845

Fax: 717-533-8661

E-mail: cust@igi-global.com

Web site: http://www.igi-global.com

Copyright ( 2018 by IGI Global. All rights reserved. No part of this publication may be reproduced, stored or distributed in any form or by any means, electronic or mechanical, including photocopying, without written permission from the publisher. Product or company names used in this set are for identification purposes only. Inclusion of the names of the products or companies does not indicate a claim of ownership by IGI Global of the trademark or registered trademark.

Library of Congress Cataloging-in-Publication Data

Names: Information Resources Management Association, editor.

Title: E-planning and collaboration : concepts, methodologies, tools, and applications / Information Resources Management Association, editor.

Description: Hershey : Engineering Science Reference, [2018]

Identifiers: LCCN 2017051713| ISBN 9781522556466 (hardcover) I ISBN

9781522556473 (ebook)

Subjects: LCSH: Digital communications--Planning.

Classification: LCC TK5103.7 .E23 2018 I DDC 384.3068/4--dc23 LC record available at https://lccn.loc.gov/2017051713

British Cataloguing in Publication Data

A Cataloguing in Publication record for this book is available from the British Library.

All work contributed to this book is new, previously-unpublished material. The views expressed in this book are those of the authors, but not necessarily of the publisher.

For electronic access to this publication, please contact: eresources@igi-global.com. 


\title{
Chapter 23 \\ Indicator Modelling and Interactive Visualisation for Urban Sustainability Assessment
}

\author{
Ruth E. Falconer \\ University of Abertay Dundee, UK \\ John P. Isaacs \\ The Robert Gordon University, UK \\ Daniel Gilmour \\ University of Abertay Dundee, UK \\ David J. Blackwood \\ University of Abertay Dundee, UK
}

\begin{abstract}
This chapter presents a novel framework for the integration of the principles of sustainable development within the urban design processes. The framework recognises that decision making for sustainable urban planning is a challenging process: requiring an understanding of the complex interactions amongst environmental, economic, and social issues. Methodologies are required that would support non-experts to become more involved in the urban design process. Towards this, the authors develop an indicator modelling and visualisation tool which comprises 1) indicator selection, 2) modelling techniques that allow spatio-temporal prediction of indicators, 3) interactive $3 D$ virtual world where visualisation techniques are used to present indicator information overlaying the virtual world to facilitate effective communication with a wide range of stakeholders. The sustainability modelling and $3 D$ visualisations are shown to have the potential to enhance community engagement within the planning process, thus enhancing public acceptance and participation within the urban or rural development project.
\end{abstract}

DOI: 10.4018/978-1-5225-5646-6.ch023

Copyright $\odot$ 2018, IGI Global. Copying or distributing in print or electronic forms without written permission of IGI Global is prohibited. 


\section{INTRODUCTION}

Sustainable development applied to urban design is an action plan set out to achieve urban sustainability and due to its multi-faceted nature it requires the effective engagement of a wide range of stakeholders e.g., planners, landscape architects, engineers, policy makers and wider communities, which is often a difficult task. These stakeholders will contribute at different stages of the urban planning process but it has been argued that urban planning and design must be fostered at the local level, involving local authorities, communities and local businesses.

A large number of tools, techniques, and guidance documents have been produced to support decision makers in achieving sustainable urban environments. Many approaches apply a sustainability assessment, characterized by an indicator set, which provides tangible information on whether things are getting better or worse. Examples of sustainability indicator sets include: the United Nations (UN) working list of Indicators of Sustainable Development (ISD's) based on Agenda 21 (Rio de Janeiro 1992), water industry (Water UK, 2000), bioenergy systems (Buchholz, Luzadis, \& Volk, 2009)and construction indicators (CIRIA, 2001). It is widely accepted that no standard set of indicators exists and indicators should be selected on a case-by-case basis (Ashley et al., 2008; Starkl \& Brunner, 2004; CIRIA, 2004). Although indicator sets exists there are still weaknesses in the approaches and methodologies that make use of these indicator sets (Walton et al., 2005). Walton et al. (2005) summarized the deficiencies of existing tools and methodologies for sustainable development as:

1. Lack of integrated and multidimensional frameworks that bring existing approaches together.

2. Lack of transparency and communication in the promotion of sustainability assessment amongst a wide-ranging group of stakeholders.

3. Lack of recognition of the context-specific nature of sustainability analysis.

4. Better inclusion of stakeholders in the assessment process.

The technical and cross discipline nature of sustainable development has been a barrier to widening stakeholder engagement. This is in confounded by the traditional methods of data communication which is typically Geographical Information Systems (GIS). GIS tools allow geospatial analysis and multiple map overlays, and are used extensively used by local authorities for communicating plans and decision making in urban planning (Drummond \& French, 2008; Harris \& Elmes, 1993; Stevens, Dragicevic, \& Rothley, 2007; States, 2000; Lodha \& Verma, 2000). It has been shown that (Lowe, 2004; Lowe, 2003) nn-expert stakeholders have difficulty in understanding data produced by GIS systems. This is in part due to complexity of the GIS software and that the user needs "to think like a geographic information scientist" (Clarke, 2001). GIS is still considered to be a complex, expert oriented tool (Traynor \& Williams, 1995) due to its enormous functionality and analysis capabilities. Its use in decision making has made it difficult for non-expert stakeholders, especially the general public, to participate fully in planning decisions (Salter, Campbell, Journeay, \& Sheppard, 2009; Al-Kodmany, 2002).

Contrastingly the role of 3D visualization in urban planning has exploded forming an increasingly important role in decision making (Isaacs, Falconer, Gilmour, \& Blackwood, 2011) and it is expected that visualizations can communicate proposals to both experts and laypersons (Downes \& Lange, 2014). This has taken the form of interactive visualizations and augmented reality applications (Bishop, 2014; Cirulis \& Brigmanis, 2013). Visualizations can be exploited to aid decision making and widen engagement as has been done in a number of fields where technical detail can be conveyed in an engaging manner: oil 
and gas industry, medical data visualization and battlefield simulations (Hix 1999). These visualizations can be further enhanced to provide information on the chosen sustainability indicator set and how this varies over space and time, a visual simulation (Isaacs, J.P., Blackwood, D., Gilmour, D. \& Falconer, 2013), dependent on the development characteristics. We propose that $3 \mathrm{D}$ visualization can be exploited for information provision in built environment, giving users views of plausible urban developments, enabling users to develop an understanding of the strengths and weaknesses associated with alternative proposals, ultimately assisting people to take more informed decisions on urban design proposal.

This chapter presents parts of an integrated framework focusing on the context-specific indicator selection, modelling and visualization of the SAVE framework applied to Dundee waterfront. This requires the selection of appropriate indicator sets, spatio-temporal modelling of indicator set, and the innovative presentation of indicators in a virtual 3D built environment (S-City VT) using aggregation methods and visualization techniques to display the indicator values. This integrated approach alleviates the shortcomings of existing sustainability methodologies identified by Walton et al. (2005) specifically addressing the need to facilitate wider stakeholder input into the planning process and an integrated approach. The reader is referred to Blackwood, Gilmour, Isaacs, Kurka, \& Falconer(2014)for the complete framework which includes a complimentary sustainability enhancement component, not discussed here, which identifies opportunities to positively influence the sustainability of the development and to devise and implement appropriate activities and actions.

\section{CASE STUDY: DUNDEE CITY WATERFRONT}

The city of Dundee is located on the north bank of the river Tay Estuary on the east coast of Scotland. The City first established itself as an important commercial hub in the 16th century due to its proximity to the Baltic and North European shipping routes via the River Tay. The city has always had close ties to the river which provided it with rich transport and trade links (McCarthy, 1995). The development of the docks site continued throughout the 17th and 18th centuries but still remained comparatively small (Dundee City Council, 2001). At the beginning of the 19th century the outbreak of the Napoleonic wars brought a period of industrial expansion of the city due to its role in the jute trade and the export of canvas and hessian (McCarthy, 1995). By the 1830s "Dundee had changed from a trading port to the world centre for the jute processing industry" and the city and its port were rapidly expanding (Dundee Waterfront, 2012). Over the next 100 years, more additions to the docks were made, "moving the city further away from the waterfront" (Dundee Waterfront, 2012). The last dock was completed in 1900 and was followed by significant decline in the Jute industry, which had a major effect on the economy of the city (McCarthy, 1995).

Dundee waterfront was largely untouched until 1960 when the City Council accepted a proposal to build a road bridge connecting Dundee to the Fife coast. Major construction of the waterfront area included the filling-in of the former docks to provide a cheap land fall for the new bridge. Dundee's central waterfront became "a 1960s highway-based solution for the Tay Road Bridge" (Scottish Executive, 2006), unattractive buildings constructed in the 1970s were to form part of a "multi-level, modernist, civic and commercial centre" which was never completed (Dundee Waterfront, 2012). These developments left the city, which had at one time been so heavily entwined with the river, completely severed from the waterfront. 
Dundee City does not follow the global trend of urbanization, since the destruction of the harbor in the 1960s and 70s Dundee's population has declined. With declining economy and population it is possible that Dundee has already become a victim of unsustainable developments. In an attempt to re-connect the city with the waterfront, Dundee City Council released the waterfront redevelopment plan. This $£ 1$ billion, 30-year project will reintegrate the city centre with the River Tay Estuary and involves the transformation of 240 ha of development land stretching $8 \mathrm{~km}$ along the River Tay. The area is divided into five focused zones: Riverside, Seabraes, the Central Waterfront, City Quay, and Dundee Port. The SAVE framework is applied to the Central Waterfront.

\section{INDICATOR SELECTION}

The first activity necessary for sustainability is the identification of a set of indicators that could provide a means of strategic monitoring of the overall sustainability of the waterfront development. It was essential that a clear understanding of the nature of the information required by stakeholders and their use of the information in the decision-making processes was attained. This ensured the appropriateness of the indicator set as a monitoring tool and also ensured that it could be fully considered by stakeholders in subsequent sustainability enhancement activities. An approach to the indicator identification and selection process was identified from a review of relevant literature (Gilmour, Blackwood, Banks, \& Wilson, 2011; Graymore, Wallis, \& Richards, 2009; Kowalski, Stagl, Madlener, \& Omann, 2009; Sheppard \& Meitner, 2005) and consists of three phases. Phase 1 involved the designing of the conceptual framework and the pre-selection of Potential Benchmark Indicators from literature. Phase 2 involved selecting and designing the indicators by a process of reduction and rationalization to identify a more manageable number of the most appropriate indicators based on an analysis of the information needs of the stakeholders. Phase 3 involved wider stakeholder interviews to finalize and adopt the indicators (Figure 1).

Figure 1. Process to identify context-specific sustainability indicators appropriate for Dundee Waterfront development (Gilmour et al., 2011).

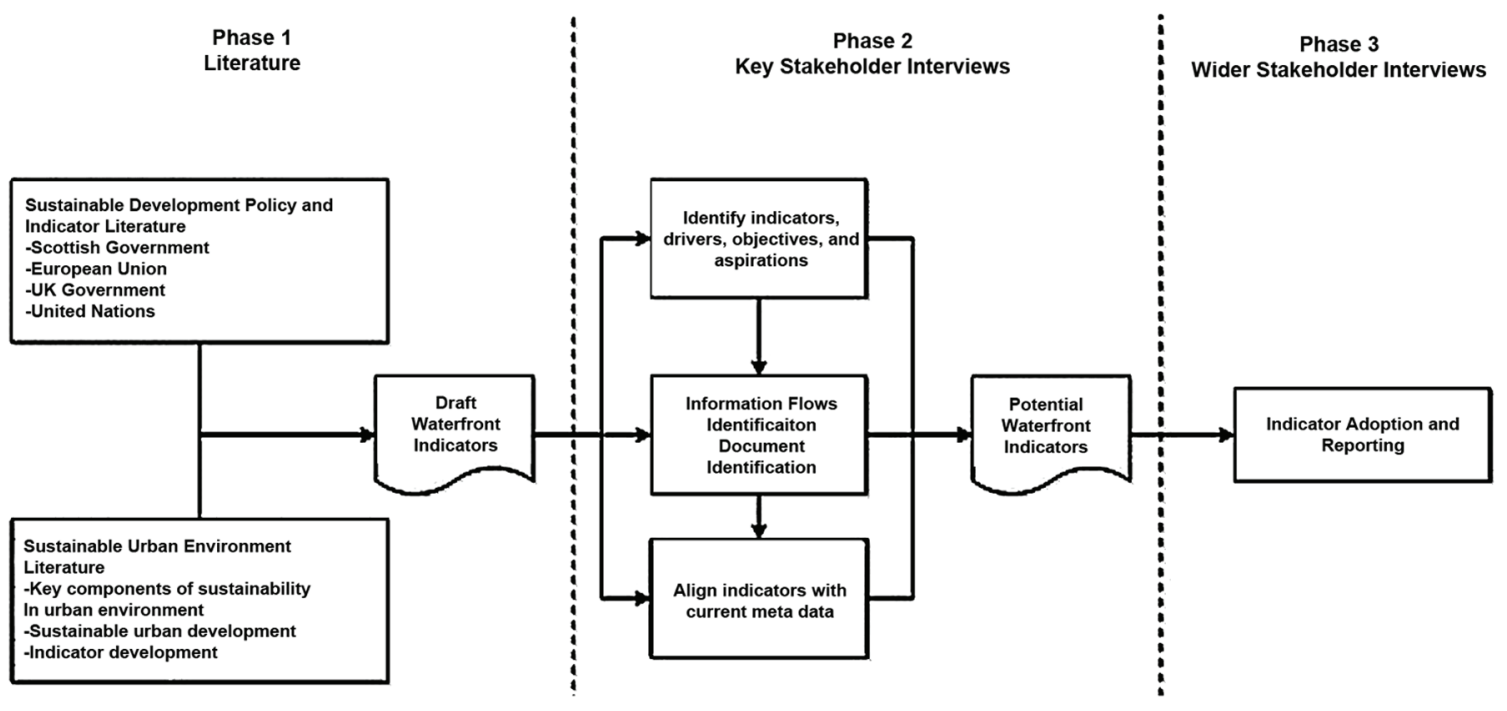


Following the process described in Figure 1, (Gilmour et al., 2011) identified a set of sustainability indicators (Table 1) that is used by the Waterfront Development Partners to monitor and enhance the sustainability of the waterfront development. Therefore a verified set of sustainability indictors covering the social, environmental and economic aspects of the development, with robust supporting data, are available.

\section{SCITY-VT INDICATOR MODELLING AND VISUALISATION}

To test if virtual 3D built environments can be exploited for sustainability information provision (SCityVT) promoting wider stakeholder engagement in the planning processes a prototyping approach was adopted. Six sustainability indicators were chosen from the indicator set to ensure that overall the reduced indicator set; (i) included two indicators from each pillar of sustainability (social, economic and environmental), (ii) represented a variety of quantitative and qualitative data (iii) included indicators with spatial and/or temporal variations, and (iv) were measurable.

A modelling and visualisation framework (S-City VT) was developed to present sustainability indicators, pertaining to different urban design scenarios to stakeholders, using bespoke software developed using C\# programming language and the XNA graphics Framework. The Microsoft XNA framework facilitates rapid game engine production by providing a set of tools utilizing a managed runtime environment. XNA essentially relieves much of the repetitive nature of creating a custom engine by providing basic methods and allowing easier access to the rendering and processing ability of computers graphics hardware. Development of the visualisation component using XNA allows the simulation component implemented using C\#, to be easily linked to the visualisation. As S-City VT is developed using XNA and $\mathrm{C \#}$ it can run as a standalone application on consumer hardware, thus requiring no specialist software such as CAD or REVIT. S-City VT can be easily distributed to public stakeholders without licensing issues. S-City VT is split into three main components, scenario design, sustainability modelling \& simulation and visualisation which are described in turn below.

\section{Scenario Design Component}

S-City VT contains a design component that allows the initial 2D plan to be recreated in 3D. The design component allows the import of architectural and 3D models which can be stored to allow representation of alternative urban design scenarios (Figure 2). Using the designer any stakeholder is able to add,

Figure 2. Steps in creating a virtual world form a $2 D$ plan

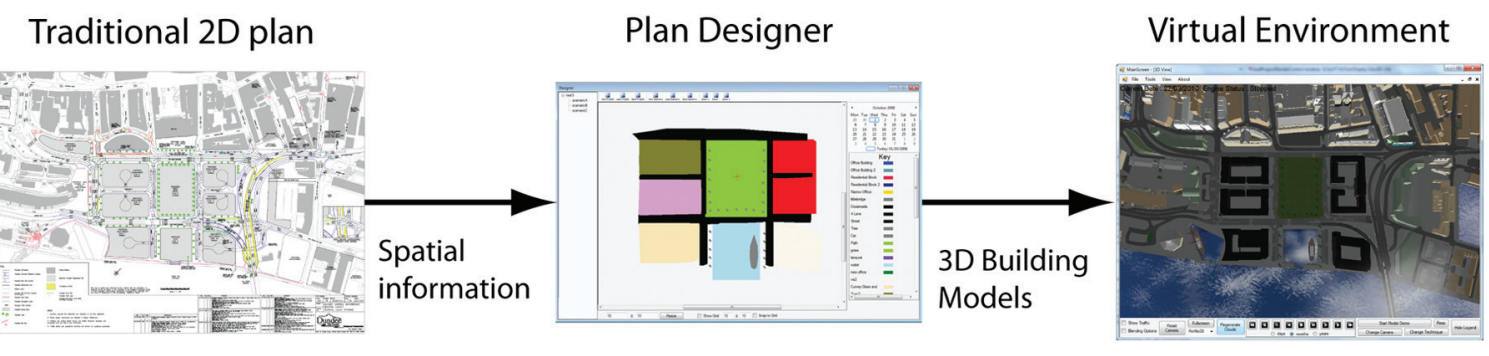


Indicator Modelling and Interactive Visualisation

Table 1. Indicator set for Dundee Waterfront afterfollowing the process described above and in Figure 1

\begin{tabular}{|c|c|c|c|c|c|}
\hline Category & Benchmark Indicators & Definition of Indicator & Units & Baseline Data & $\begin{array}{c}\text { Desired Direction/ } \\
\text { Target }\end{array}$ \\
\hline \multirow{10}{*}{ Economic } & $\begin{array}{l}\text { Demographics } \\
\text { (City Wide) }\end{array}$ & Population retention & Population number & 142,170 & UP \\
\hline & $\begin{array}{l}\text { Retention of skills base (City } \\
\text { Wide) }\end{array}$ & Graduate retention rate & Graduate population & $33 \%$ & Up \\
\hline & $\begin{array}{l}\text { Knowledge based } \\
\text { employment } \\
\text { (City Wide) }\end{array}$ & $\begin{array}{l}\text { Knowledge economy sector } \\
\text { jobs }\end{array}$ & $\begin{array}{l}\text { Percentage share of jobs in } \\
\text { knowledge industries }\end{array}$ & $28.8 \%(09 / 10)$ & Up \\
\hline & $\begin{array}{l}\text { Employment } \\
\text { (City Wide) }\end{array}$ & Employment rates & $\begin{array}{l}\% \text { of resident working age } \\
\text { population }\end{array}$ & $72.2 \%$ & Up \\
\hline & $\begin{array}{l}\text { Capacity to stimulate } \\
\text { investment } \\
\text { (Direct) }\end{array}$ & $\begin{array}{l}\text { Total inward investment to } \\
\text { waterfront }\end{array}$ & $£$ Inward investment & 0 & Up \\
\hline & $\begin{array}{l}\text { Tourism numbers } \\
\text { (City Wide) }\end{array}$ & $\begin{array}{l}\text { Tourists visiting city centre } \\
\text { locations }\end{array}$ & Number & $\begin{array}{c}53,535 \\
(-9.5 \%) \\
72,061(+16.8 \%) \\
2008\end{array}$ & Up \\
\hline & $\begin{array}{l}\text { Tourism } \\
\text { (City Wide) }\end{array}$ & $\begin{array}{l}\text { Level of tourism expenditure } \\
\text { Dundee }\end{array}$ & Expenditure & $£ 130.79$ million & Up \\
\hline & $\begin{array}{l}\text { Regeneration } \\
\text { (Direct) }\end{array}$ & Increased property value & $\%$ Increase & 0 & Up \\
\hline & $\begin{array}{l}\text { Job creation } \\
\text { (Direct) }\end{array}$ & Number of jobs created & Number & 0 & UP \\
\hline & $\begin{array}{l}\text { Economic output } \\
\text { (City Wide) }\end{array}$ & Economic output & GDP per capita & $£ 17335$ & Up \\
\hline \multirow{4}{*}{ Environmental } & $\begin{array}{l}\text { Water* } \\
\text { (Direct) }\end{array}$ & Per capita water use & 1/head/day P.E. & Not yet available & $\begin{array}{l}\text { Target - to match } \\
\text { national best practice }\end{array}$ \\
\hline & $\begin{array}{l}\text { Noise } \\
\text { (Direct) }\end{array}$ & Noise level impact & $\begin{array}{l}\text { Number of complaints related } \\
\text { to DCW construction }\end{array}$ & 0 & Down \\
\hline & $\begin{array}{l}\text { Energy } \\
\text { (Direct) }\end{array}$ & Energy consumption & $\begin{array}{l}\text { Energy use } / \mathrm{CO}_{2} \text { per } \mathrm{M} 2 \text { of } \\
\text { property }\end{array}$ & N/A & $\begin{array}{l}\text { Target - to match } \\
\text { national best practice }\end{array}$ \\
\hline & $\begin{array}{l}\text { Travel } \\
\text { (City Wide) }\end{array}$ & $\begin{array}{l}\text { Journeys to work and school } \\
\text { made by pubic or active } \\
\text { transport }\end{array}$ & $\%$ Journeys & $15 \%$ & Up \\
\hline \multirow{7}{*}{ Social } & $\begin{array}{l}\text { Housing provision } \\
\text { (Direct) }\end{array}$ & Residential development & $\%$ of residential development & $21 \%$ & $21 \%$ \\
\hline & $\begin{array}{l}\text { Health \& Well being } \\
\text { (City Wide) }\end{array}$ & $\begin{array}{l}\text { Positive and sustained } \\
\text { destinations } \\
\text { (education, higher education, } \\
\text { employment or training) }\end{array}$ & $\begin{array}{l}\% \text { of school leavers in positive } \\
\text { and sustained destinations }\end{array}$ & $\begin{array}{l}85 \% \\
(2007)\end{array}$ & increase \\
\hline & $\begin{array}{l}\text { Community } \\
\text { (City Wide) }\end{array}$ & Neighbourhood satisfaction & $\begin{array}{l}\% \text { Resident satisfaction with } \\
\text { the quality of and access to } \\
\text { local services, facilities and } \\
\text { environment }\end{array}$ & $\begin{array}{c}\text { Quality } 83 \% \\
\text { Access } 93 \% \text { City } \\
\text { Wide }\end{array}$ & Up \\
\hline & $\begin{array}{l}\text { Active community } \\
\text { participation } \\
\text { (City Wide) }\end{array}$ & $\begin{array}{l}\text { Informal and formal } \\
\text { volunteering }\end{array}$ & $\begin{array}{l}\% \text { adults who volunteer } \\
\text { regularly }\end{array}$ & $17 \%$ & UP \\
\hline & $\begin{array}{l}\text { Acceptability } \\
\text { (Direct) }\end{array}$ & Acceptability to stakeholders & $\%$ & $96 \%$ & Up \\
\hline & $\begin{array}{l}\text { Confidence } \\
\text { (City Wide) }\end{array}$ & Public perception of Dundee & $\begin{array}{l}\text { Qualitative: } \\
\text { Very good } \\
\text { Good } \\
\text { Neither } \\
\text { Poor } \\
\text { Very poor }\end{array}$ & $\begin{array}{c}18 \\
49 \\
24 \\
7 \\
2\end{array}$ & UP \\
\hline & $\begin{array}{l}\text { Amenity value } \\
\text { (City Wide) }\end{array}$ & $\begin{array}{l}\text { Public perception of amenity of } \\
\text { Waterfront area }\end{array}$ & Qualitative & Not yet available & Excellent \\
\hline
\end{tabular}


remove or rearrange components of the urban design. These changes are reflected immediately in the $3 \mathrm{D}$ virtual world, not requiring the environment to be re-rendered for display as would normally be the case using a CAD based system.

Whilst the designer is strongly linked to the visualisation it is also strongly coupled to the modelling and simulation. Changing a building attributes such as size, position or building material, using the designer, will not only update the buildings appearance in the virtual world but may affect the indicator modelling. For example changing the material attributes of a building may impact on its energy efficiency.

\section{Modelling and Simulation}

The indicator modeling involves developing separate indicator models that define how each of the indicators varies over space and time. For the prototype application six sustainability indicators were chosen from the full indicator set identified by (Gilmour et al., 2011) and empirical models developed. The six indicators selected for modeling provide a spread across the sustainability domains (economy, society and environment) and were identified as having readily available data at the beginning of the case study. S-City VT is not designed to provide absolute measures of sustainability but to allow the relative sustainability of different scenarios to be compared by non-experts. The models described here are simple in their construction and can be replaced with more detailed models if required, but our main objective was to determine if information provision related to sustainability can be presented and is useful to non-expert stakeholders. The models used in the prototype application are detailed below. The model output was normalization $(0-100)$, the process of conversion of diverse unit cardinal scores into dimensionless indicators, where 0 is the lowest sustainability index and 100 is the highest sustainability index. Intermediate scores were determined on a linear 'min-max' basis (Rowley, Peters, Lundie, \& Moore, 2012) with the exception of the non-linear noise model.

\section{Energy Efficiency}

The energy efficiency model is based on the Nation Calculation Method (NCM), which is the industry standard allowing energy efficiency of buildings to be determined (BRE, 2009). The NCM method takes into account a wide range of factors, including number of doorways, glazing type, exterior construction, and number of floors, among other aspects, to produce a metric describing the energy efficiency of the building. A NCM report was created using the NCM tool, characterizing the typical buildings in the development for a number of design options where external appearance (glass, brick) and different mixes of building use (residential, commercial) varied as shown in Figure 3.

This data is input into the energy efficiency model and attenuated with the temporal energy consumption data, which reflects how energy use of the buildings change depending on seasonality. Figure 4 shows how the energy use sustainability index changes as a function of time for two different building types and use (e.g., glass, commercial and brick, residential). Whilst the Energy Efficiency indicator model provides an adequate representation of the patterns of energy use in the buildings for prototype testing, other parts of the NCM methodology such as building ventilation, heating or cooling and orientation will be included in future developments of S-City VT. 
Figure 3. Graph showing temporal changes in the energy use index due monthly energy fluctuations

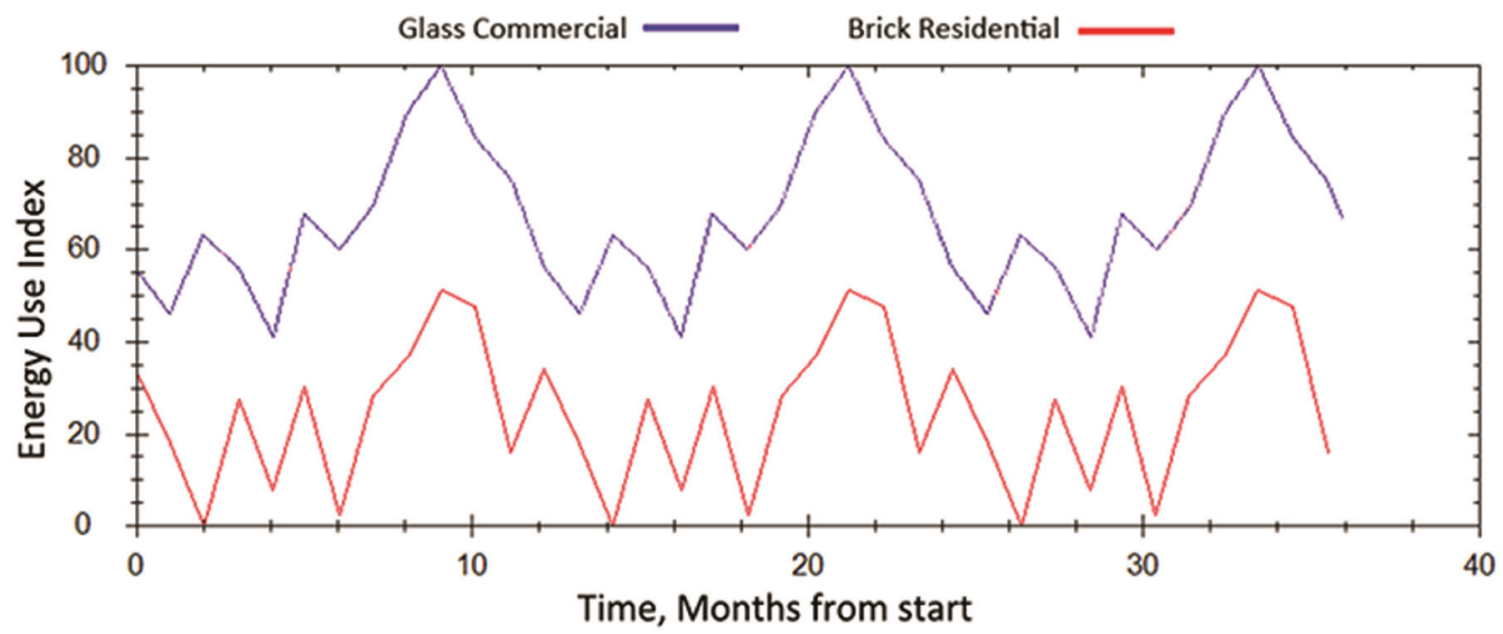

\section{Noise Pollution}

The noise model calculates the levels of traffic noise received at each building and calculates the proportion of people that would deem that noise level unacceptable. Projected traffic flow data for the waterfront development was sourced from Dundee Waterfront Traffic \& Signaling Report ("NPL Acoustics: Technical Guides - Calculation of Road Traffic Noise 1988,"1998). For each road in the proposed 3D virtual development a noise level is calculated from the projected hourly traffic flow. Using a function (Equation 1) provided in CRTN (1988), this traffic flow can be transformed into a noise level in decibels $(\mathrm{dB}(\mathrm{A}))$ (Figure 4) .

Basic hourly noise level $L_{10}=42.2+10 \log _{10} q d B(A)$

Figure 4. Prediction of the log10 basic noise level hourly in terms of total hourly flow

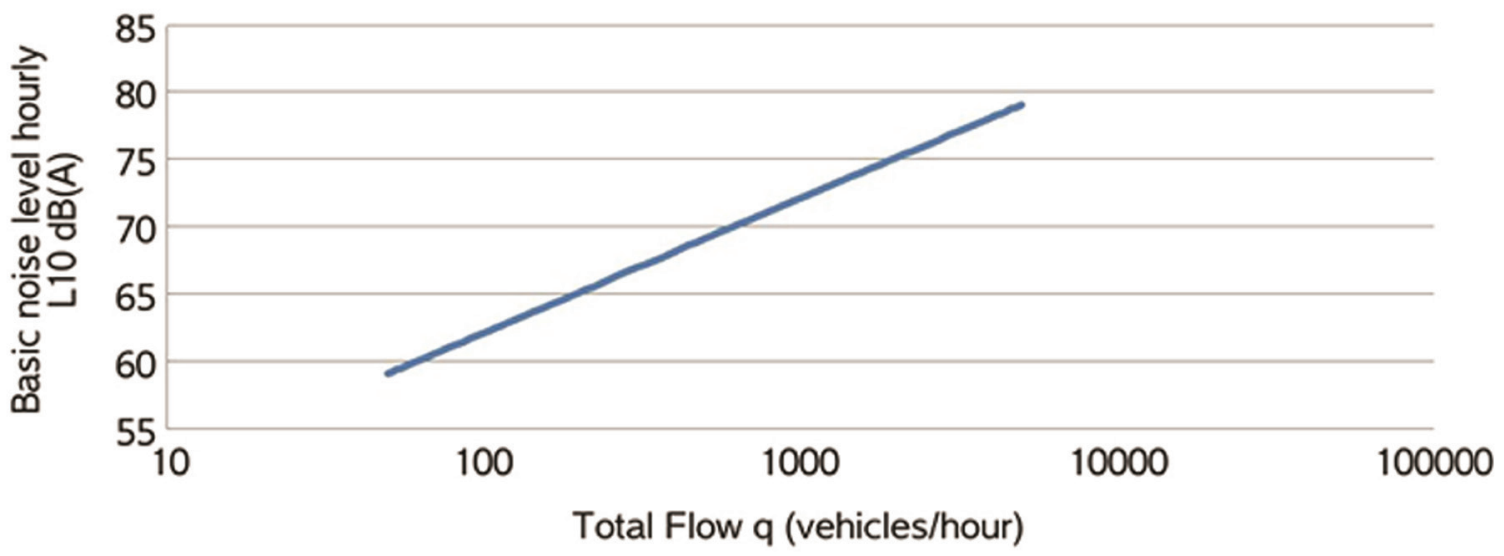


A noise level 'heard' at each building based on its location and the traffic volume is calculated based on the shortest Euclidean distance (d) between the noise source (road) and the building (Figure 5). The sound level emanating from each road is obtained by correcting the basic noise level using Equation 2. The equation also includes the height (h) of the listener which is assumed constant in these calculations (CRTN, 1988).

Noise Level Correction $=-10 \log _{10}\left(d^{\prime} / 13.5\right) d B(\mathrm{~A}$ where $d^{\prime}=$ shortest slant disatnce from the road $\times\left[(d+3.5)^{2}+h^{2}\right]^{(1 / 2)}$

To determine the total noise level received by the building the corrected noise from each road must be summed over $\mathrm{n}$ roads in the development (Equation 3 ).

\section{Total noise level}

$=10 \log _{10}\left[\sum_{1}^{n} A n t i \log _{10}\left(L_{n} / 10\right)\right] d B(A)$

Each building has a noise level representing the total level of external noise received at that building location in relation to the roads and their projected traffic flows. The internal noise level in the building would also be influenced by factors such as the building construction materials and these can be included in future versions of S-City VT. Our sustainability index in the prototype is achieved by normalizing the noise level (0-100 scale as before) and applying a non linear function (Equation 4 - ("Design Manual for

Figure 5. Building distance from traffic noise source

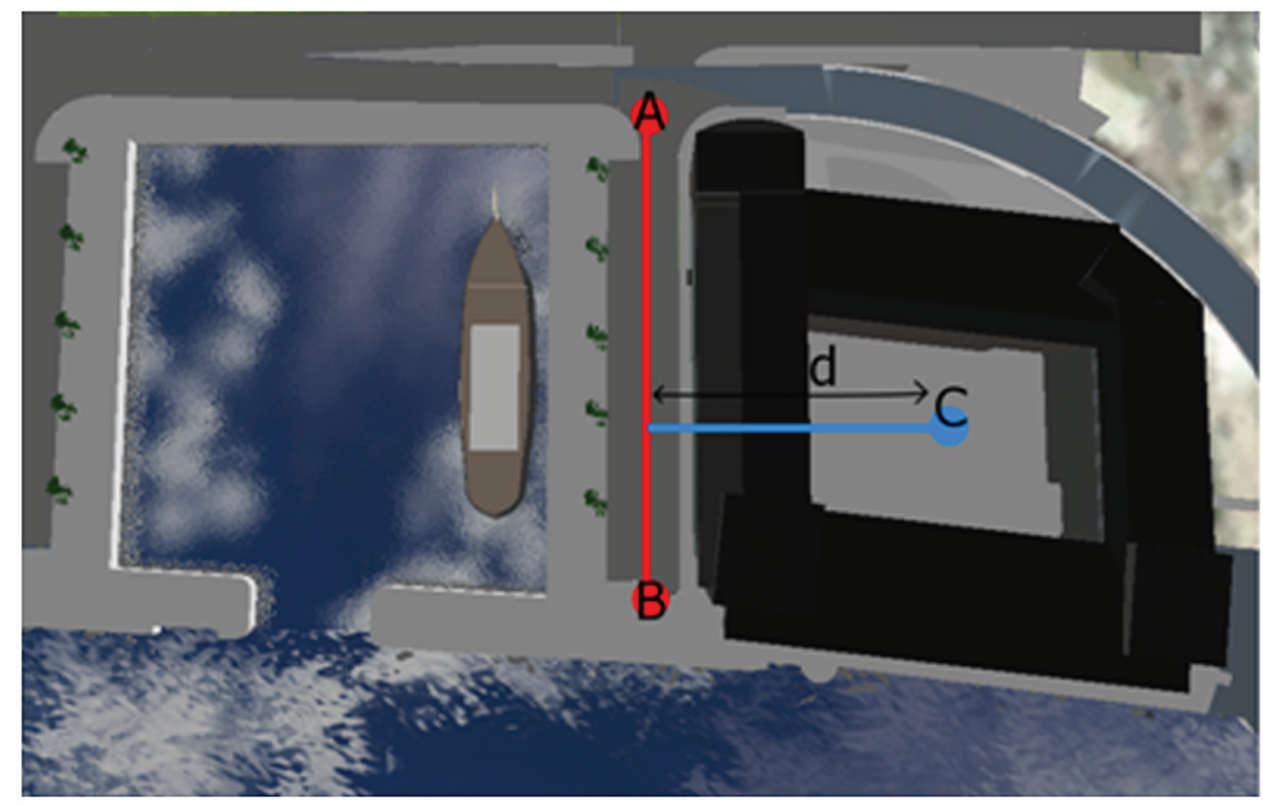


Roads and Bridges (DMRB) I Standards for Highways," 1994)), this calculates the percentage of people that will be bothered by a specific noise level.

$$
\begin{aligned}
& \text { \% Bothered } \\
& =\frac{100}{\left(1+e^{(-\grave{u})}\right)}, \text { where } \grave{u}=0.12(\operatorname{LdB}(A))-9.08
\end{aligned}
$$

\section{Economic Benefit}

There were a number of economic indicators identified for the Dundee Central Waterfront Development. The net present value of the buildings was chosen as the selected indicator for the prototype as it allowed time as a factor. The economic model utilizes a discounted cash flow calculation to determine the worth of a buildings current cash flow for a specific point in time. The calculation uses a discount rate which allows the cash flows to be discounted back to their present worth. The use of discounting in sustainability assessment is a topic of considerable debate (Stern, 2006). On one hand it would appear unethical to value benefits to future generation at a lower level than we value them to ourselves but there is also inter-generational inequity if discounting is ignored where there might be an expectation that future generations will be richer. The inclusion of a discounting mechanism in the modeling allows such issues to be explored. Comparison of urban design scenarios and sensitivity testing on the impact of assumptions on discount rates can be explored in S-City VT.

Net Present Value

$=C F_{0}+\frac{C F_{1}}{\left(1+r_{1}\right)}+\frac{C F_{2}}{\left(1+r_{2}\right)^{2}}+\ldots+\frac{C F_{t}}{\left(1+r_{t}\right)^{t}}$

where $\mathrm{CF}=$ cash flow for that year, $\mathrm{r}=$ discount rate for that year, $\mathrm{t}=$ the year.

In the equation the capital cost for the construction of the first building is represented by $\mathrm{CF}_{0}$. Capital costs of subsequent buildings will be discounted to this point time.

Each building in the model has a site preparation and construction phase, during this time the cash flow for that period is taken as zero as the building is neither sold or being rented. The model is able to reflect the differences between cash flows for rented and sold buildings. Buildings which are sold will take a large income at the point of sale. As the building has been sold further cash flows for this building will be zero. The discount factor will also apply to the sale income so for two buildings of equivalent value, a building sold in year one will have a higher present value than building sold in year ten. As the building has been sold the upkeep and maintenance of the building will be borne by the buyer and so it is not modeled here. Buildings which are rented will take a smaller income every year. Rented buildings may have a rent free period, to encourage tenants, and will have a lay period between leases, during these times the cash flow for that period will be zero. A discount factor is applied to the yearly income to determine its present value, based on the time in years from construction (Figure 6).

The initial cost of the buildings are calculated using the building type (e.g. residential, commercial, retail, social) and the cost per square meter for that type of building. The income from sale or rent is 
Figure 6. Present value for a single building, built in year 0, showing differences between leased and sold income with different discount rates

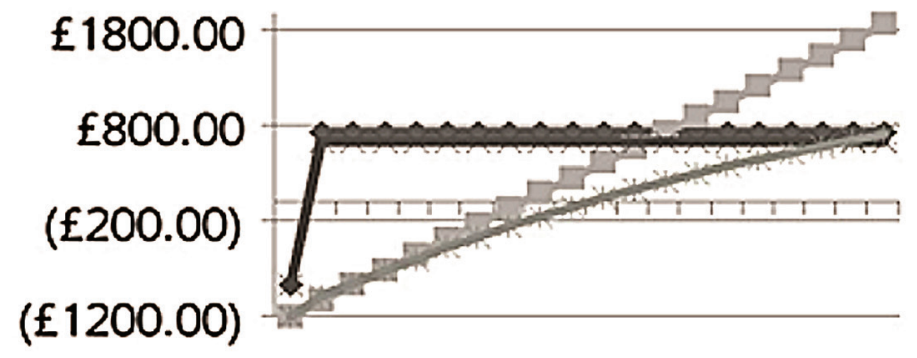

\section{$\leadsto$ Sold no discount - - Leased no discount - Sold $5 \%$ discount Leased $5 \%$ discount}

likewise calculated using the projected income for that building type. These values were sourced from the Scottish Enterprise Tayside economic report on the waterfront development. The maximum and minimum vales are then mapped onto 0-100 and linearly interpolated.

\section{Acceptance of Building Use}

Social acceptance was identified by the waterfront stakeholders as a key sustainability indicator. This was assessed in terms of the public acceptance of possible building uses within the proposed development. The master plan for Dundee has been developed and through discussion with Dundee council the possible building uses were determined. These are commercial office space, retail units, cafe/bar/ restaurant and residential space. A survey was undertaken to determine the preference of building use of a range of stakeholders. The survey used a ranking system where the participant was asked to rank possible building uses in order of preference. A statistical test (Friedman test using SPSS) was performed on the mean rank of each building use. The results of the Friedman test show that there is a significant difference $(\mathrm{p}<0.001)$ between how the users ranked the different building uses. Combined with posthoc analysis of the results it is possible to rank the acceptability of the building uses in the following order; Leisure (highest ranked), Retail \& Residential (equal ranked) and Commercial (Lowest Ranked). To create a sustainability index for the acceptability of each building these rankings are mapped onto a 0-100 scale, with Leisure at 100 (highest sustainability), Retail \& Residential at 50 and Commercial (lowest sustainability) at 0 .

\section{Housing Provision and Employment}

The housing provision and Employment models are simple. The Housing provision is calculated by determining the percentage of buildings designated as residential and this is mapped directly onto the sustainability index of 0-100. The Employment model uses existing information regarding different building uses (e.g., commercial, leisure, etc.), and building sizes to provide likely numbers of jobs a specific building might create or sustain given its use and size. More sophisticated models that include jobs created during construction and differentiate between types of jobs created or sustained can be incorporated as data becomes available. Again the maximum and minimum values are then mapped onto 0-100 and linearly interpolated. 


\section{Multicriteria Opinion Analysis}

One of the problems with traditional sustainability assessment is involving the views and experiences of a wide range of stakeholders (Isaacs, Falconer, Gilmour, \& Blackwood, 2010). Many of the traditional methods of aggregating indicator values, such as Multi Attribute Utility Theory (MAUT), lack transparency leaving the users in a position where they do not fully understand how the resulting weightings have been derived. Stakeholder engagement in the aggregation of the indicator values is addressed in the selection of the ANP multi-criteria analysis approach, the main strength of which lies in providing the stakeholders with the ability to include their own personal knowledge and opinions of indicator interactions through the use of pair-wise comparisons (Saaty, 2004). The Analytical Network Process (ANP) method uses interactive network structures which give a more holistic representation of the overall problem. Components of the problem are connected, as appropriate, in pairs with directed lines simulating the influence of one component over another. The components in a network may also be regarded as elements that interact and influence each other in regard to a specific attribute.

To perform an ANP analysis the decision maker must identify the clusters, elements and the relationships and interactions between them. Once the network is constructed a supermatrix describing the interactions defined in the network (Gencer \& Gürpinar, 2007) is created. Once the supermatrix is created using the fundamental scale and pair-wise method then every interaction is described in terms of every element it interacts with (Saaty, 2004). Once this has been completed the normalised eigenvector calculated from the matrix will generate the normalised prioritised list of elements.

ANP allows cross-cluster interactions as well as inter-relationships between elements, as opposed to similar methods such as AHP which require the decision to be hierarchical. It is structured naturally and allows for a more realistic representation of the problem, but its main strength lies in providing the user with the ability to include their own personal knowledge and opinions about an interaction through the use of pair-wise comparisons.

The prototype application allows the user to apply the ANP method to the indicators being modelled, thus defining the network that connects them. The prioritised lists of elements which are derived from the ANP analysis are used in the 3D visualisation to provide a weighting to the indicators being visualised. For example, in the blend method the weightings are used to determine how much of each indicator colour scale contributes to the final blended colour representing the aggregated indicators. For the images shown below equal weighting has been given to the indicators, however since SCity-VT allows users to create their own weights for a set of indicators, the consequences of different weightings on urban sustainability can be explored (Figure 7).

\section{VISUALISATION}

As discussed traditional GIS does not provide a realistic physical representation of the city or development being proposed. CAD systems do enable the creation of 3D models which provide the user with a realistic representation of the buildings and the developments (Al-Kodmany, 2002). However, CAD systems provide no ability to overlay additional data and provide little context beyond the building or area being studied. Furthermore CAD systems cannot be seamlessly integrated with simulations.

The visualisation combines GIS and 3D urban models and embeds the 3D models in the surrounding landscape to contextualise the urban area of focus. The ability to visualise part of the city that is undergo- 
Figure 7. The S-City VT framework

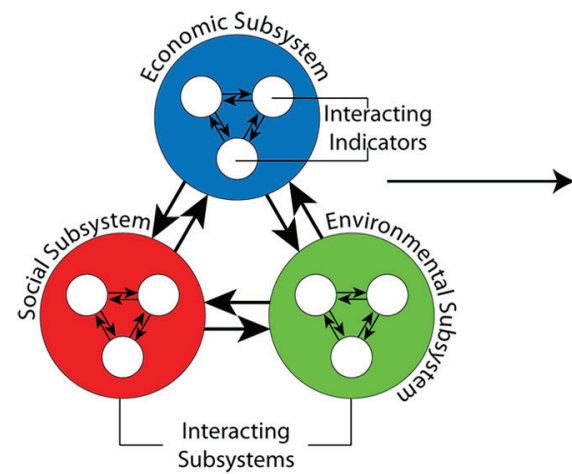

Simulation Engine:

Environmental, Social and Economic indicator Models

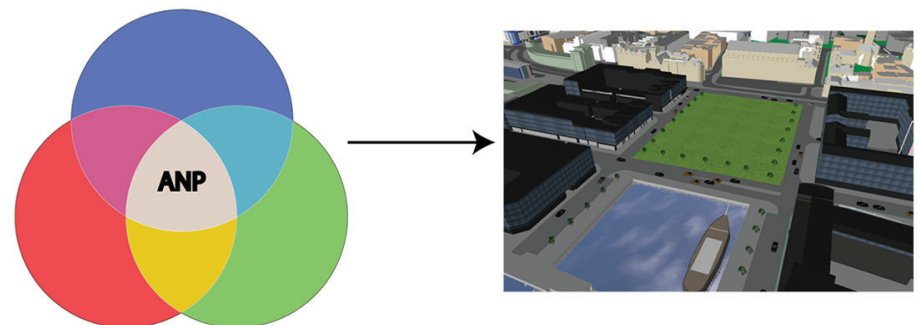

Opinion Analysis:

Analytic Network Process, multi-criteria analysis of user opinion and experience
3D Visualisation:

Virtual environment \& visualisation techniques

ing the development or regeneration within the wider city context is likely to improve engagement and bring a greater level of involvement from all participants in the planning process (Levy, 1995)

The user will have interactive control enabling them to view the proposed development from any conceivable viewpoint. Weather and lighting effects can also be manipulated allowing the development to be seen in a different context (Figure 8). This may enable the user to become fully immersed in the proposed development, to a much greater degree than 2D plans, GIS, or rendered 3D stills.

The virtual representation of the built environment represents the outward appearance and design of the development scenarios. The visualisation is however also designed to show the results of the indicator modelling and associated weightings through different visualisation techniques. Previous research (Savic, Kapelan, \& Walters, 2005) highlights that most existing tools provide a single method to view data and this limits data accessibility and information provision. By providing a number of methods, visualisation techniques, to present the sustainability indicator data it is hoped that users are not constrained to a single view and can use the method that they prefer. The visualization techniques described below generate textures or colour maps using the graphics libraries of XNA, the textures are recomputed each model time step, reflecting the temporal changes in indicator values, and sent to the visualisation system to map onto the building geometry. This approach is only possible by having seamless integration of visualisation and simulation.

Figure $8.3 D$ representation of proposed development within the city-wide context with different lighting and weather conditions

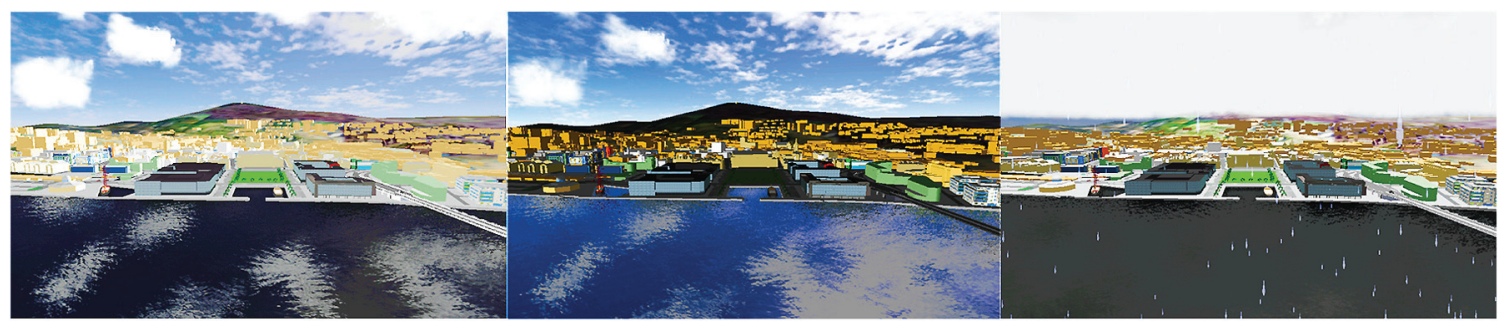




\section{Blending}

The simplest visualisation method involves combining the six sustainability indices, calculated by the simulations, into a single sustainability index. This single value is then mapped to a single colour scale. The user is able to select from a number of colour scales suggested by Levkowitz \& Herman (1992), which are known for allowing greater discrimination between values. These include the hot-cold, heated object, magenta, local optimised and spectral colour scales. Using the hot-cold scale demonstrated in Figure 9, a building or floor with high relative sustainability would appear blue while a building with low sustainability would appear red. This provides the user with a simple way of identifying which scenario is the most sustainable based on the relative sustainability, which is color mapped, provided by the indicator modelling and then aggregated using ANP.

\section{Weaving}

As opposed to the blending method, which combines the six indicator values into a single indicator, the weaving technique is designed to preserve some of the underlying information and indicator aggregation by ANP is not applied. This enables the user to identify which indicators differ across urban designs when they are compared side by side. The colour weaving technique (Hagh-Shenas, Kim, Interrante, $\&$ Healey, 2007) uses a different colour scale for each indicator (Figure 10) to attempt to preserve this information. The colours from each scale are then randomly weaved into a patchwork like texture which is applied to each floor of the building. The size of the squares or patches in the weave can also be changed depending on the user's preferences. A small patch size will give an overall representation of the sustainability, with darker shades representing low sustainability and lighter shades representing higher sustainability. A larger patch size will allow user to identify quickly which colours stand out the most, and therefore which indicators are having the greatest impact.

\section{Traditional Graphical Techniques}

Radar graphs (Figure 11) allow the stakeholder to compare the sustainability of different buildings based on the indicator values. The shape, size, colour and point values will be different for each building allowing a detailed comparison.

Figure 9. Overview of the indicator blending technique

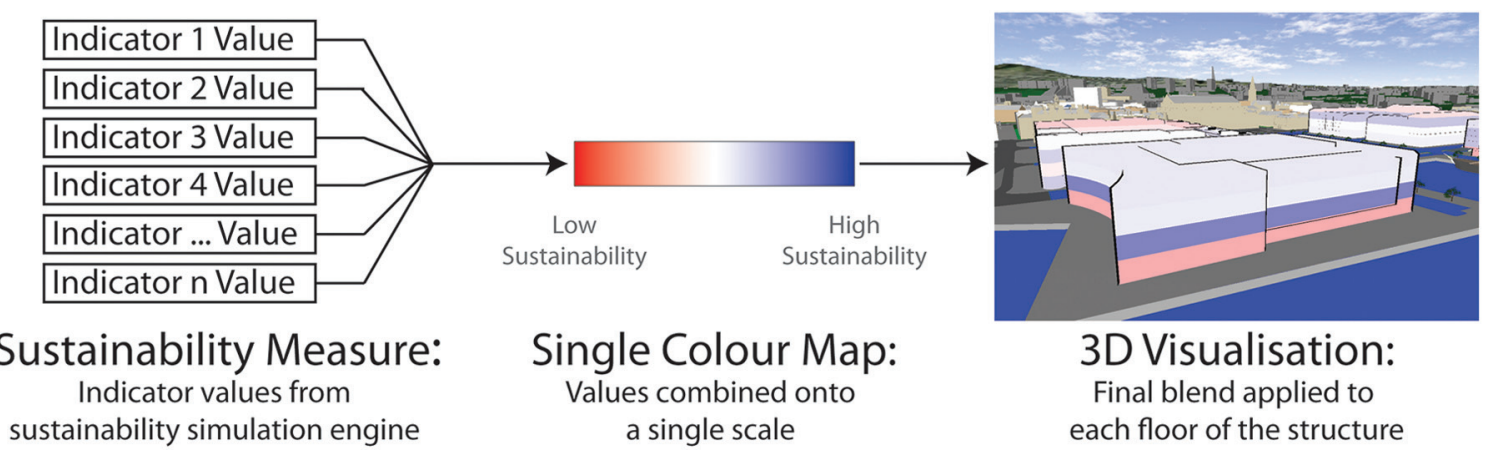


Figure 10. Overview of the indicator weaving technique

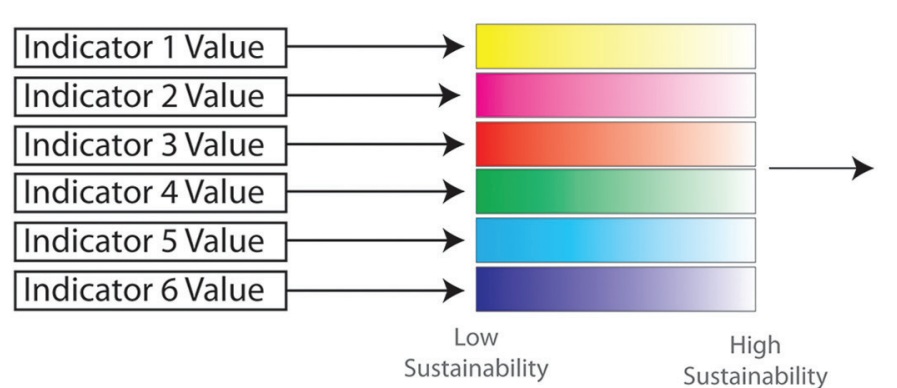

Sustainability Measure: Indicator values from sustainability simulation engine
Multiple Colour Maps: Sustainability measure for each indicator normilised and mapped onto its own scale

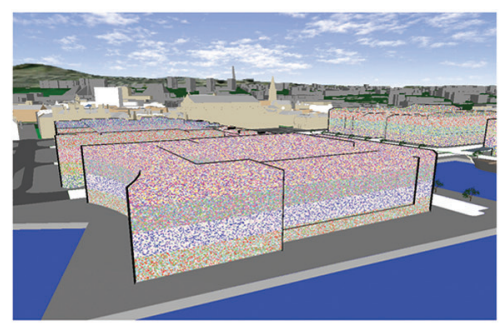

3D Visualisation:

Colours combined to create a weave which is applied to each floor of the structure

Figure 11. Comparison of scenarios using traditional radar graphs

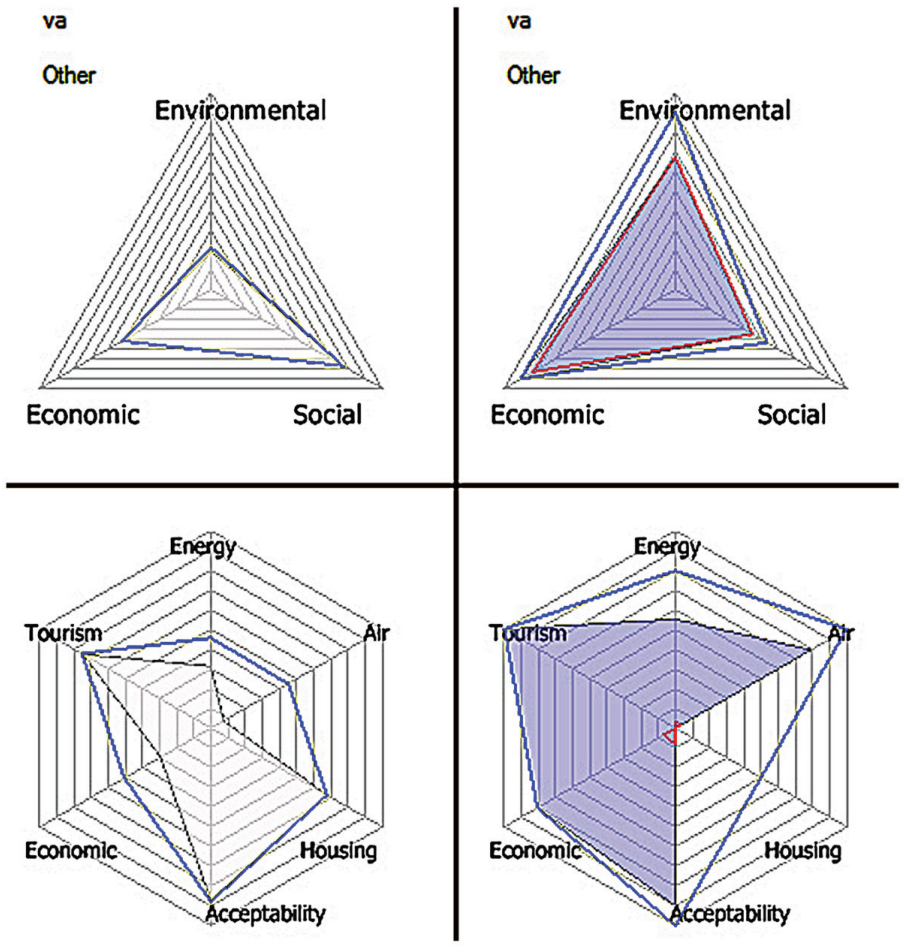

Parallel coordinates allow the user to compare all indicator values for all the buildings in a scenario (Figure 12). Buildings can be selected and their trace in the graph is highlighted.

Simple temporal graphs plot all the indicator values over the life time of the development. These allow the user to identify the interconnectivity of the indicators and to identify where and why sudden changes occur (Figure 13). 
Figure 12. Parallel coordinate graph for sample development

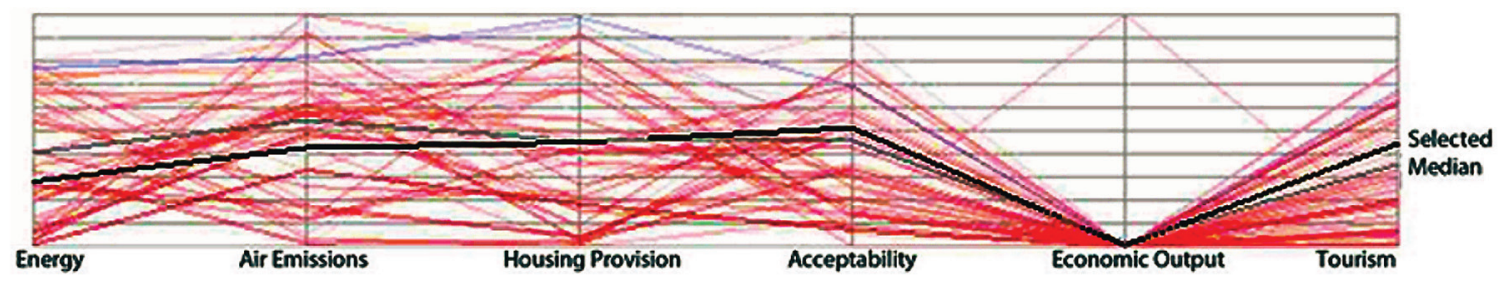

Figure 13. Indicator graph showing changes in 6 indicators over time

Temporal Sustainability

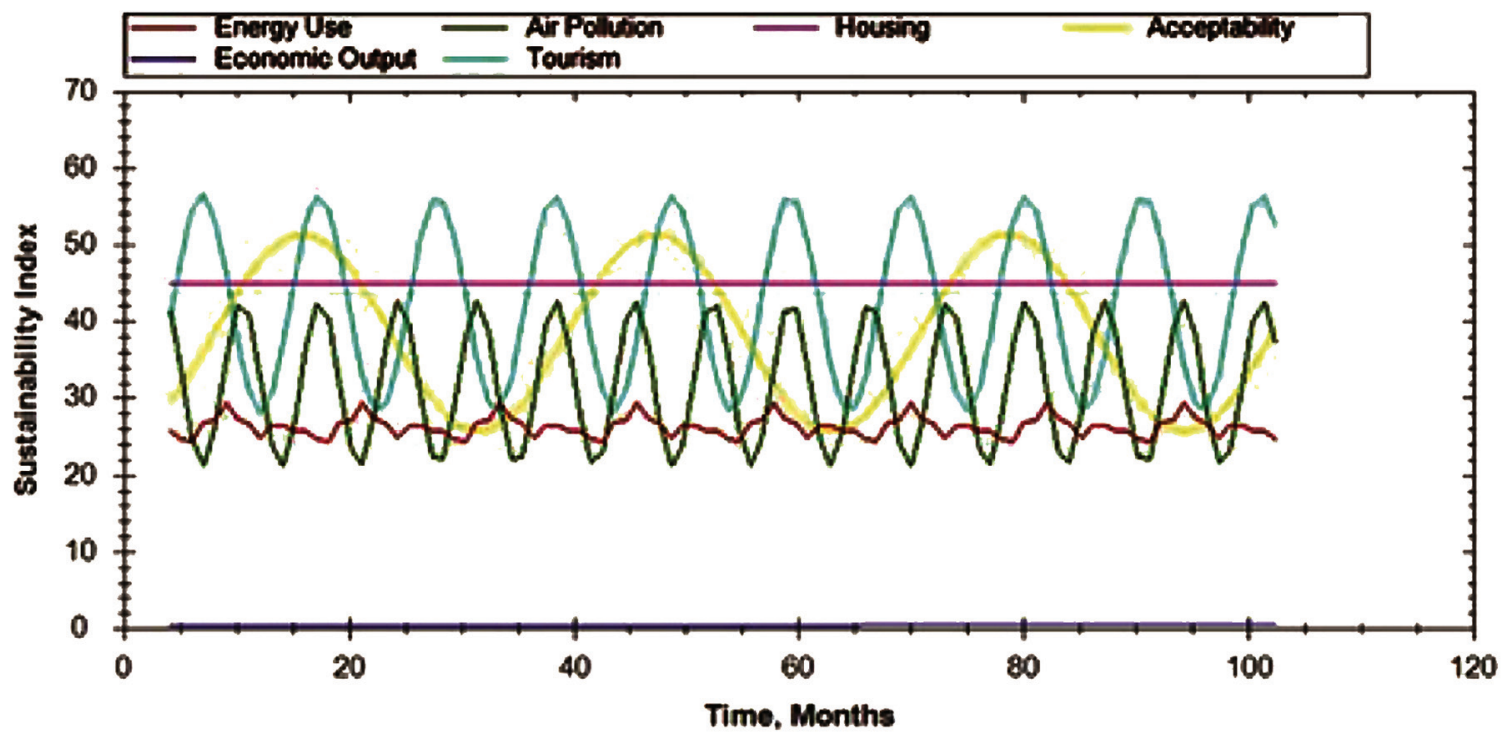

The visualisation utilises a split screen rendering approach which allows the user, using any of the techniques, to compare two scenarios side by side throughout the life cycle of the development. A number of visualisation techniques have been used to display the results of the indicator models which allows the user to not only compare the physical appearance of the different scenarios but also the relative sustainability of each scenario (Figure 14).

\section{S-CITY VT PILOT EVALUATION: TESTING THE EFFECTIVENESS OF COMMUNICATING THE SUSTAINABILITY}

The pilot consists of a single group testing session and aims to determine if the prototype can communicate differences in sustainability indicators relating to different urban designs. The group was a community-based group and comprised 8 participants. The participants were presented with simulation output of 11 sets of two urban design scenarios. The two urban design scenarios were presented using a split screen method where the two urban designs differed in relative sustainability - the left and right hand urban design is scenario $1 \& 2$ respectively. Relative sustainability is defined as the difference in 
Figure 14. Visualisation techniques used in S-City VT to allow comparison of scenarios in a split screen environment: top - realistic representation of external building appearance; middle - weaving technique showing a number of indicator values; bottom - blending technique combining a number of indicator values into a single indicator

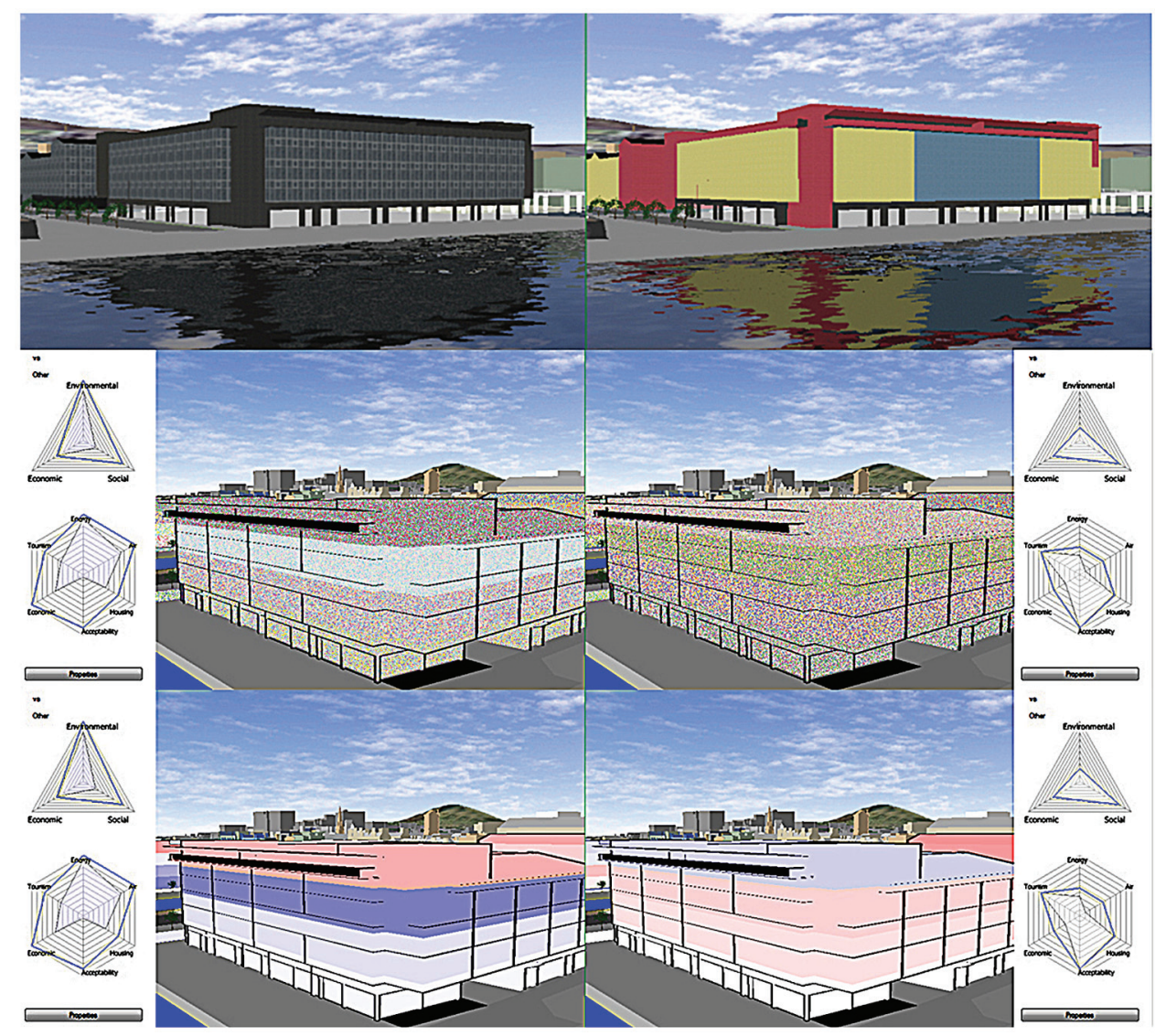

the derived sustainability score between the two urban designs. Alternative urban designs were constructed that had relative differences in sustainability of $0,2,4,6,8,10,20,40,60,80$ and 100. The images were presented in a random order as in Table 1. Figure 17 shows 3 example simulation outputs presented to the community group where the difference in the sustainability score is 0,2 and $100 \%$ (in Figure 15 a, b \& c, respectively).

The blend results presented in Table 2 show that participants were extremely adept in identifying the differences between the two scenarios. Where the participants identified the correct answer, i.e. most sustainable urban design, green shading is applied to the cell. Table 2 show that the group successfully identified which scenario was the most sustainable in all cases.

The testing was repeated with the weave visualization technique, and the 11 constructed urban designs were presented with the weave technique where the difference in relative sustainability is 0,2 and $100 \%$ as in Figure 16 a, b \& c. For the weave technique the group was also able to correctly identify the scenario that was most sustainable in all of the 11 cases, as well as identify which indicators were the causes of the difference in sustainability between the two scenarios. 
Figure 15. Screenshots of 3 of the 11 blend tests encapsulating the sustainability indicators, as presented in Table 1, presented to the community group where the difference in the two urban designs sustainability score is 0, 2, and $100 \%$ in figures $a, b \& c$
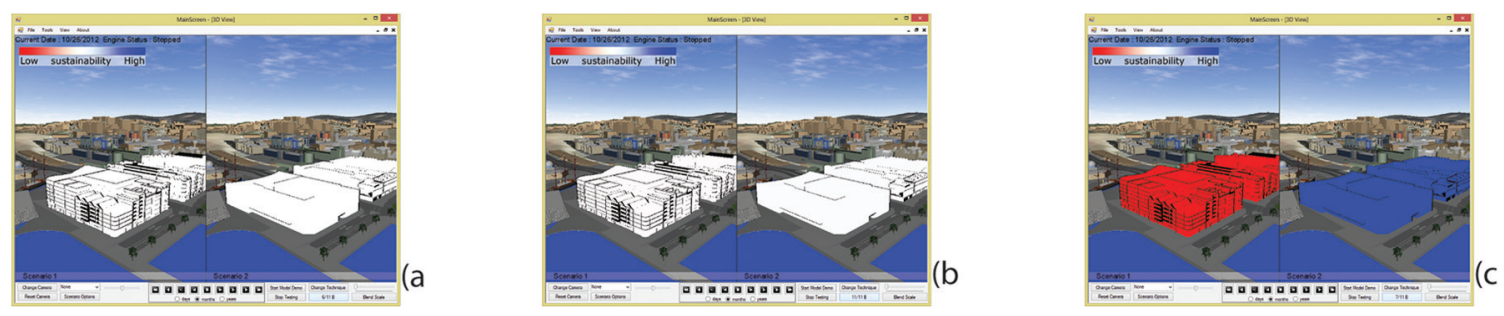

Table 2. Eleven tests of blend technique, participants correctly identified which scenario was most sustainable - where the relative sustainability differed by 0,2, 4, 6, 8, 10,20, 40 60, $80100 \%$ results of comparisons using the blend technique. The correctly identified scenarios are shaded green.

\begin{tabular}{|c|c|c|c|}
\hline Test & Chosen & \multicolumn{2}{|c|}{ Actual } \\
\hline Blend & Scenario & Scenario & \% Difference \\
\hline 1 & 2 & 2 & 80 \\
\hline 2 & 1 & 1 & 100 \\
\hline 3 & 1 & 1 & 8 \\
\hline 4 & 2 & 2 & 4 \\
\hline 5 & 1 & 1 & 20 \\
\hline 6 & 2 & 2 & 40 \\
\hline 7 & 1 & 1 & 2 \\
\hline 8 & 1 & 0 & 6 \\
\hline 9 & 0 & 2 & 60 \\
\hline 10 & 2 & 2 & \\
\hline 11 & 2 & & 0 \\
\hline
\end{tabular}

Figure 16. Three of the eleven weave tests, as described in Table 3, presented to the community group, where the difference in relative sustainability is 0, 2 and $100 \%$ in figures $a, b \& c$
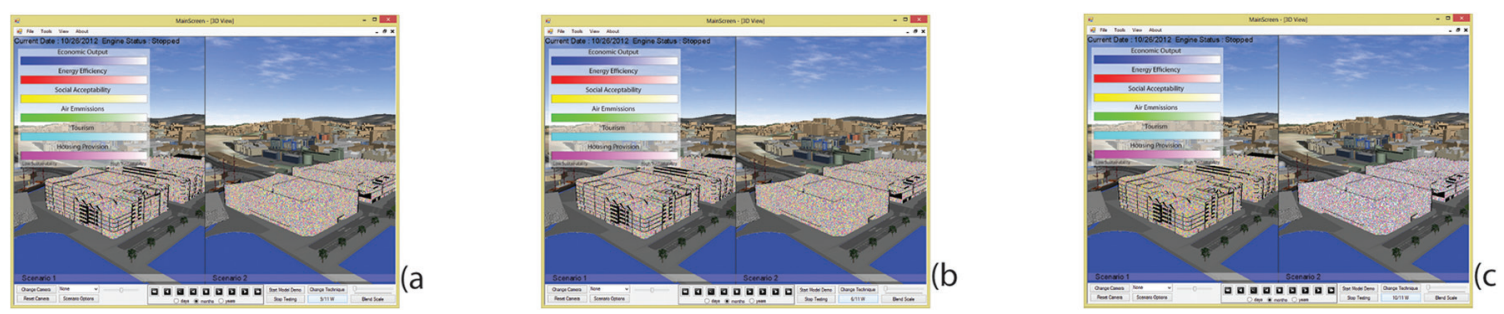
Table 3. Eleven tests of weave technique, participants correctly identified which scenario was most sustainable an all 11 cases (green shading) - where the relative sustainability differed by 0, 2, 4, 6, 8, 10, 20, 40 60, 80 100\% results of comparisons using the weave technique. The indicator that was the origin of the difference was also correctly identified in all cases.

\begin{tabular}{|c|c|c|c|c|c|}
\hline \multirow{2}{*}{$\frac{\text { Test }}{\text { Weave }}$} & \multicolumn{2}{|c|}{ Participant Selection } & \multicolumn{3}{|c|}{ Most Sustainable Scenario } \\
\hline & Scenario & Indicator & Scenario & $\%$ Difference & Indicator \\
\hline 1 & 2 & housing & 2 & 100 & housing \\
\hline 2 & 2 & employment & 2 & 80 & employment \\
\hline 3 & 2 & housing & 2 & 20 & housing \\
\hline 4 & 2 & economic & 2 & 40 & economic \\
\hline 5 & 0 & None & 0 & 0 & \#N/A \\
\hline 6 & 2 & economic & 2 & 4 & economic \\
\hline 7 & 2 & energy & 2 & 8 & energy \\
\hline 8 & 1 & noise & 1 & 6 & noise \\
\hline 9 & 1 & economic & 1 & 60 & economic \\
\hline 10 & 2 & energy & 2 & 2 & energy \\
\hline 11 & 1 & housing & 1 & 10 & housing \\
\hline
\end{tabular}

The results of the pilot study demonstrate that the visualization clearly has the potential to provide sustainability information to stakeholders. The same focus group approach was applied to three different stakeholder groups with similar findings.

\section{CONCLUSION AND FUTURE DEVELOPMENTS}

It is clear that new methodologies are required in urban planning and design to: provide an integrated view of sustainability assessment, promote wider inclusion in the decision making process and aid transparency and communication in the promotion of sustainability. The $3 \mathrm{D}$ visualization component, of the SAVE methodology, was successful in widening stakeholder engagement achieved by the positive reaction to, and interpretation of, the visual display of sustainability indicator data by a range of stakeholders. The use of 3D visualization to determine difference between scenarios was successfully presented, although whether the virtual world can promote understanding of the interdependent facets of urban sustainability is another matter. This should be tested further to determine if visualization can change people's level of knowledge and views of urban sustainability. Further development and testing of the visualization tool is planned during the building design stage and the tool has been extended for use in a BIM context.

\section{REFERENCES}

NLP Acoustics. (1988). Technical guides - Calculation of road traffic noise 1988. Retrieved February 03, 2015, from http://resource.npl.co.uk/acoustics/techguides/crtn/ 
Al-Kodmany, K. (2002). Visualization tools and methods in community planning: From freehand sketches to virtual reality. Journal of Planning Literature, 17(2), 189-211. doi:10.1177/088541202762475946

Ashley, R., Blackwood, D., Butler, D., Jowitt, P., Davies, J., Smith, H., \& Oltean-Dumbrava, C. et al. (2008). Making asset investment decisions for wastewater systems that include sustainability. Journal of Environmental Engineering, 134(3), 200-209. doi:10.1061/(ASCE)0733-9372(2008)134:3(200)

Bishop, I. D. (2014). Location based information to support understanding of landscape futures. Landscape and Urban Planning. doi:10.1016/j.landurbplan.2014.06.001

Blackwood, D. J., Gilmour, D. J., Isaacs, J. P., Kurka, T., \& Falconer, R. E. (2014). Sustainable urban development in practice: The SAVE concept. Environment and Planning. B, Planning \& Design, 41(5), 885-906. doi:10.1068/b39080

BRE. (2009). National calculation method. Available at: http://www.ncm.bre.co.uk/

Buchholz, T., Luzadis, V. A., \& Volk, T. A. (2009). Sustainability criteria for bioenergy systems: Results from an expert survey. Journal of Cleaner Production, 17, S86-S98. doi:10.1016/j.jclepro.2009.04.015

CIRIA (Construction Industry Research and Information Association). (2001). Sustainable construction- Company indicators: WS Atkins consultants. CIRIA, London, Publication C563.

CIRIA (Construction Industry Research and Information Association). (2004). Sustainable construction-Implementing targets and indicators: Experiences from Ciria's pioneer's club. CIRIA, London, Publication C633.

Cirulis, A., \& Brigmanis, K. B. (2013). 3D outdoor augmented reality for architecture and urban planning. Procedia Computer Science, 25, 71-79. doi:10.1016/j.procs.2013.11.009

Clarke, K. C. (2001). Getting started with geographic information systems. Prentice Hall Upper Saddle River.

CRTN. (1988). Calculation of road traffic noise. London: HMSO.

Design Manual for Roads and Bridges (DMRB) Standards for Highways. (1994). Retrieved February 03, 2015, from http://www.standardsforhighways.co.uk/dmrb/

Downes, M., \& Lange, E. (2014). What you see is not always what you get: A qualitative, comparative analysis of ex ante visualizations with ex post photography of landscape and architectural projects. Landscape and Urban Planning. doi:10.1016/j.landurbplan.2014.06.002

Drummond, W. J., \& French, S. P. (2008). The future of GIS in planning: Converging technologies and diverging interests. Journal of the American Planning Association, 74(2), 161-174. doi:10.1080/01944360801982146

Dundee City Council. (2001). Dundee Central Waterfront Development Masterplan.

Dundee Waterfront. (2012). Dundee waterfront website. Retrieved November 7, 2012, from http://www. dundeewaterfront.com/ 
Fuchs, H., Levoy, M., \& Pizer, S. M. (1989). Interactive visualization of 3D medical data. Computer, 22(8), 46-51. doi:10.1109/2.35199

Gencer, C., \& Gürpinar, D. (2007). Analytic network process in supplier selection: A case study in an electronic firm. Applied Mathematical Modelling, 31(11), 2475-2486. doi:10.1016/j.apm.2006.10.002

Gilmour, D., Blackwood, D., Banks, L., \& Wilson, F. (2011, March 1). Sustainable development indicators for major infrastructure projects. In Proceedings of the ICE - Municipal Engineer. Thomas Telford. Retrieved from http://www.icevirtuallibrary.com/content/article/10.1680muen.800020

Graymore, M. L. M., Wallis, A. M., \& Richards, A. J. (2009). An index of regional sustainability: A GIS-based multiple criteria analysis decision support system for progressing sustainability. Ecological Complexity, 6(4), 453-462. doi:10.1016/j.ecocom.2009.08.006

Hagh-Shenas, H., Kim, S., Interrante, V., \& Healey, C. (2007). Weaving versus blending: A quantitative assessment of the information carrying capacities of two alternative methods for conveying multivariate data with color. IEEE Transactions on Visualization and Computer Graphics, 13(6), 1270-1277. doi:10.1109/TVCG.2007.70623 PMID:17968074

Harris, T. M., \& Elmes, G. A. (1993). The application of GIS in urban and regional planning: A review of the North American experience. Applied Geography (Sevenoaks, England), 13(1), 9-27. doi:10.1016/0143-6228(93)90077-E

Hix, P. (1999). User-centered design and evaluation of a real-time battlefield visualization virtual environment. Graphics, 12(1), 89-95.

Isaacs, J., Falconer, R., Gilmour, D., \& Blackwood, D. (2010). (in press). Enhancing urban sustainability using 3D visualisation. Proceedings - Institution of Civil Engineers.

Isaacs, J., Falconer, R., Gilmour, D., \& Blackwood, D. (2011). Enhancing urban sustainability using 3D visualisation. Proceedings Of The ICE-Urban Design and Planning., 164(3), 163-174.

Isaacs, J. P., Blackwood, D., Gilmour, D., \& Falconer, R. E. (2013). Real-time visual simulation of urban sustainability. International Journal of E-Planning Research, 2(1), 20-42.

Kowalski, K., Stagl, S., Madlener, R., \& Omann, I. (2009). Sustainable energy futures: Methodological challenges in combining scenarios and participatory multi-criteria analysis. European Journal of Operational Research, 197(3), 1063-1074. doi:10.1016/j.ejor.2007.12.049

Levkowitz, H., \& Herman, G. T. (1992). Color scales for image data. IEEE Computer Graphics and Applications, 12(1), 72-80. doi:10.1109/38.135886

Levy, R. M. (1995). Visualization of urban alternatives. Environment and Planning. B, Planning \& Design, 22(3), 343-358. doi:10.1068/b220343

Lodha, S. K., \& Verma, A. K. (2000). Spatio-temporal visualization of urban crimes on a GIS grid. ACM. doi:10.1145/355274.355300 
Lowe, R. (2004). Interrogation of a dynamic visualization during learning. Learning and Instruction, 14(3), 257-274. doi:10.1016/j.learninstruc.2004.06.003

Lowe, R. K. (2003). Animation and learning: Selective processing of information in dynamic graphics. Learning and Instruction, 13(2), 157-176. doi:10.1016/S0959-4752(02)00018-X

McCarthy, J. (1995). The Dundee waterfront. Land Use Policy, 12(4), 307-319. doi:10.1016/02648377(95)00029-D

Rowley, H. V., Peters, G. M., Lundie, S., \& Moore, S. J. (2012). Aggregating sustainability indicators: Beyond the weighted sum. Journal of Environmental Management, 111, 24-33. doi:10.1016/j.jenvman.2012.05.004 PMID:22813856

Saaty, T. L. (2004). Fundamentals of the analytic network process - Dependence and feedback in decision-making with a single network. Journal of Systems Science and Systems Engineering, 13(2), 129-157. doi:10.1007/s11518-006-0158-y

Salter, J. D., Campbell, C., Journeay, M., \& Sheppard, S. R. J. (2009). The digital workshop: Exploring the use of interactive and immersive visualisation tools in participatory planning. Journal of Environmental Management, 90(6), 2090-2101. doi:10.1016/j.jenvman.2007.08.023 PMID:18558460

Savic, D. A., Kapelan, Z., \& Walters, G. A. (2005). Decision-support tools for sustainable urban development. Proceedings of the ICE - Engineering Sustainability, 158(3), 135-142. doi:10.1680/ ensu.2005.158.3.135

Scottish Executive. (2006). Choosing our future. Sustainable Development Indicator Set. Measuring Progress on Scotland's Sustainable Development Strategy.

Sheppard, S. R. J., \& Meitner, M. (2005). Using multi-criteria analysis and visualisation for sustainable forest management planning with stakeholder groups. Forest Ecology and Management, 207(1-2), 171-187. doi:10.1016/j.foreco.2004.10.032

Starkl, M., \& Brunner, N. (2004). Feasibility versus sustainability in urban water management. Journal of Environmental Management, 71(3), 245-260. doi:10.1016/j.jenvman.2004.03.004 PMID:15158287

States, U. (2000, September). A summary of models for assessing the land-use patterns. Environmental Protection.

Stern, N. (2006). Stern review on the economics of climate change. London: HM Treasury.

Stevens, D., Dragicevic, S., \& Rothley, K. (2007). iCity: A GIS-CA modelling tool for urban planning and decision making. Environmental Modelling \& Software, 22(6), 761-773. doi:10.1016/j.envsoft.2006.02.004

Traynor, C., \& Williams, M. G. (1995). Why are geographic information systems hard to use? In Conference companion on Human factors in computing systems - CHI '95 (pp. 288-289). New York: ACM Press; doi:10.1145/223355.223678

UKWIR - 00/EQ/14/1 - A Working Set of Environmental Sustainability Indicators for the UK Water Industry. (20002). Retrieved February 03, 2015, from http://www.ukwir.org/ukwirlibrary/154 
Walton, J. S., El-Haram, M., Castillo, N. H., Horner, R. M. W., Price, A. D. F., \& Hardcastle, C. (2005). Integrated assessment of urban sustainability. In Proceedings of Institution of Civil Engineers; Engineering Sustainability (pp. 57-65). Academic Press.

Water, U. K. (2000). Towards environmental sustainability: UK water industry environmental sustainability indicators. London: Water UK.

\section{KEY TERMS AND DEFINITIONS}

Agenda 21: Non-binding, voluntarily implemented action plan of the United Nations with regard to sustainable development.

Energy Efficiency: The efficiency of the built environment with respect to energy use and retaining energy.

Indicator Modeling: A means to predict how sustainability indicators will change in the future.

Indicators of Sustainable Development: Measurable indicators that inform whether the development is meeting its sustainability objectives.

Noise Pollution: Is the disturbing or excessive noise that may harm the activity or balance of human or animal life.

Sustainable Urban Environments: Environments economically viable, equitable and non-compromising to the natural environment.

Virtual 3D Built Environment: A 3D environment constructed using a software package of the built environment.

This research was previously published in Emerging Issues, Challenges, and Opportunities in Urban E-Planning edited by Carlos Nunes Silva, pages 188-209, copyright year 2015 by Engineering Science Reference (an imprint of IGI Global). 